\title{
Characterization of Vaginitis Among Women Complaining of Genital Tract Symptoms
}

\author{
Hemin Muheddin Kareem \\ Nursing Department \\ Technical College of Health \\ Sulaimani Polytechnic University \\ Sulaimani, Iraq \\ hemin.kareem@spu.edu.iq
}

Safa Bakr Karim

Anesthesia Department

Technical College of Health

Sulaimani Polytechnic

University Sulaimani, Iraq

Safa.bakr@spu.edu.iq

\section{Hozan Hallmat}

Medical Laboratory Department

Technical College of Health

Sulaimani Polytechnic

University Sulaimani, Iraq

hozanhalmat22@gmail.com

\section{Shakar Aziz}

Medical Laboratory Department Technical College of Health

Sulaimani Polytechnic

University Sulaimani, Iraq

Shakar.aziz123@gmail.com

Nawa Latif

Medical Laboratory Department

Technical College of Health

Sulaimani Polytechnic

University Sulaimani, Iraq

Nawah99@gmail.com

\author{
Muhammed Saed Qadir \\ Medical Laboratory Department \\ Technical College of Health \\ Sulaimani Polytechnic University \\ Sulaimani, Iraq \\ Muhammed.qadir@spu.edu.iq \\ Solaf Jawhar Ali \\ Nursing Department \\ Technical College of Health \\ Sulaimani Polytechnic University \\ Sulaimani, Iraq \\ Solaf.jawhar@spu.edu.iq

\section{Nawal Wrya} \\ Medical Laboratory Department \\ Technical College of Health \\ Sulaimani Polytechnic University \\ Sulaimani, Iraq \\ nawalwrya@gmail.com
}

\section{Aya Ahmad}

Medical Laboratory Department Technical College of Health Sulaimani Polytechnic University Sulaimani, Iraq ayaahmeed98@gmail.com

\footnotetext{
Shadya Mhammad Rasul

Medical Laboratory Department Technical College of Health

Sulaimani Polytechnic University Sulaimani, Iraq

mhammadshady@gmail.com
}

\begin{tabular}{l} 
Article Info \\
\hline Volume 5 - Special Issue: $4^{\text {th }}$ \\
International Conference on the Health \\
and Medical Science : Medical \\
Researches Improve Life Quality \\
(ICHMS 2020) \\
DOI: \\
10.24017/science.2020.ICHMS2020.17
\end{tabular}

\begin{abstract}
Vaginitis is the inflammation of the vagina as a result of a change in the balance of normal flora affecting women of reproductive age. It is one of the most frequent reasons that women visit clinics. The objective of this study was to determine the importance of laboratory diagnosis methods in the treatment of the disease and to study the symptoms and risk factors associated with vaginitis among
\end{abstract}




\section{Article history:}

Received: 05 October 2020

Accepted: 11 October 2020

\section{Keywords:}

Vaginitis, diagnosis, culture symptoms, microscope examination. women with genital tract symptoms. Vaginal swabs were collected from 50 women attending Maternity hospital and Chwarchra dormitory camps in Sulaimani city. Samples were examined microbiologically and causative agents were isolated. All relevant clinical information such as patient demographic profiles, socioeconomic variables, risk factors and symptoms have been collected by questionnaire based study. Different species of microorganisms were isolated from vaginal samples including yeast and bacteria. Culture analysis and gram stain had shown that bacterial vaginosis was $22 \%$, while the rate of yeast infection was $16 \%$. The higher percentage was $62 \%$ for the normal flora (Lactobacillus). Microscopic examination of patient's vaginal swabs revealed that $63.6 \%$ of infectious group had high level of epithelial cells (>10), while the most patients with non-infectious vaginitis had (10) or less epithelial cell in the microscopic field. The presence of epithelial cell was significantly associated with infectious vaginitis (p-value 0.04). Most patients were aged between 25-35 years. The result showed a significant association between infectious vaginosis with education level (p-value 0.02). The most common symptom present among patients with infectious vaginitis group was itching (38.5\%) and smelly discharge (40\%). The majority of women had history of previous infections in both infectious and non-infectious vaginitis groups.

Furthermore, there was different types of vaginitis including infectious vaginitis (bacterial and yeast infection) and non-infectious vaginitis. Therefore, it is essential to perform laboratory examination for the patients to detect the causative agents of vaginitis, and ensure the most appropriate treatment can be administered. In addition, the treatment of vaginitis can be done by topical application of Lidocaine 5\% ointment (as a local anesthetic) nightly for seven weeks has been shown to decrease the pain of vaginitis in women.

Copyright (C) 2020Kurdistan Journal of Applied Research.

All rights reserved.

\section{INTRODUCTION}

Many pathogens are responsible for different sexually or non-sexually transmitted diseases and may use the genital tract as the entry point. Vaginitis is the inflammation of the vagina as a result of changing the balance of normal flora and is common in women of reproductive age. Vaginitis has several causes, the most common of which is infections caused by yeast, bacteria and parasites. Such infections are termed vaginosis. The most common types of vaginitis is bacterial vaginosis (40-50\%), vaginal candidiasis (20-25\%), and trichomoniasis (15-20\%); yet in $7-72 \%$ of women with vaginitis, the specific cause remains undiagnosed. In the US, 
approximately $30 \%$ of women in the United States with complaints of vaginal discharge or irritation remain undiagnosed, despite wide testing.

The most common symptoms of vaginitis include change in odor, color or amount of vaginal discharge. This is often combined with other symptoms including vaginal irritation or itching, painful urination, pain during intercourse, and light vaginal bleeding or spotting. Different methods are used to diagnose vaginitis according to the severity of infection, for example, clinical presentations, physical examination, $\mathrm{pH}$ level of the vagina, microscopy, and laboratory tests mainly based on microbial cultures. Vaginal discharge often varies depending on the cause of the infection, for example, thick, cruddy discharge, itching and irritation are classic signs of yeast infection. However, none of these symptoms are specific for vulvovaginal candidiasis, and in the case of asymptomatic bacterial vaginosis, it difficult to rely on clinical symptoms. Microscopic examination of vaginal secretion is a more reliable method to diagnose trichomoniasis, vulvovaginal candidiasis and bacterial vaginitis. However, this method is affected by the experience level of the examiner and the numbers of the pathogens that are present in the specimen[1]. Vaginal cultures is the most effective method to diagnose vulvovaginal candidiasis, especially with recurrently symptomatic patients, although it does take longer to obtain results. Candida can be identified via morphology and the isolation of yeast growing on differentiation media [2].

Understanding the cause of the inflammation means the most appropriate treatment can be given. Bacterial vaginitis is treated with antibiotics such as ceftriaxone (Rocephin), clindamycin (Cleocin), erythromycin, cefixime (Suprax), doxycycline (Doryx), metronidazole (Flagyl), and azithromycin (Zithramax). The antibiotic treatments can be administered in various forms including include intravaginal cream, oral antibiotics, and via injection. In the case of yeast infections, antifungal medications such as terconazole (Terazol), fluconazole, clotrimazole (Gyne-Lotrimin), butoconazole (Gynazole), miconazole (Monistat), and Nystatin are used. A Trichomonas infection is treated with metronidazole (Flagyl)[3].

The diagnosis of vaginal infection among women in Maternity hospital is currently dependent on the clinical symptoms without performing any laboratory examinations. The aim of this study is to determine the importance of laboratory diagnosis methods in the treatment of the disease. Furthermore, we aim to study the symptoms and risk factors associated with vaginitis among women with genital tract symptoms. In addition, the treatment of vaginitis can be done by topical application of Lidocaine 5\% ointment (as a local anesthetic) nightly for seven weeks has been shown to decrease the pain of vaginitis in women. Another anesthetic (numbing) treatment which can be applied to the vulva is EMLA cream. It contains (EMLA cream) two active ingredients which are Lidocaine $2.5 \%$ and prilocaine $2.5 \%$, which are used to numb areas of the skin that would otherwise feel pain.

\section{METHODS AND MATERIALS}

The samples were collected in Maternity hospital and Chwarchra dormitory camps in Sulaymaniyah city. The first step in evaluation of vaginitis was done by obtaining all relevant clinical information such as patient demographic profiles, socioeconomic variables, risk factors, symptoms and previous treatments. The data have been collected by a questionnaire based study. Sample analysis was performed in the microbiology laboratory of Maternity hospital in Sulaymaniyah city. Samples were taken from the vagina with the aid of a speculum and sterile cotton swabs. One sample were collected from each of the patients and transported immediately to the microbiology lab. The swab was inoculated for culture in different media including macConkey agar, mannitol salt agar, blood agar and chocolate agar (Biomark Laboratories, Pune 411 04, India). Next, the swab was used for the preparation of the wet mount and a thin smear on the microscopic slide for the direct examination. Finally after $48 \mathrm{~h}$ incubation at $37^{\circ} \mathrm{C}$, gram staining was performed for the identification of the vaginal infections. Ethical clearance was obtained from the Maternity teaching hospital and patients 
were recruited after obtaining their informed consent.

\section{RESULTS AND DISCUSSION}

Fifty patients with genital tract symptoms were included in this cross sectional study and all patients invited accepted to participate. The study extended from November 2019 to February 2020. Different species of microorganisms were isolated from vaginal samples including yeast and bacteria, which are presented in figure 1. Culture analysis and gram stain had shown that the rate of bacterial vaginosis was $22 \%$, while the rate of yeast infection was $16 \%$, with normal flora (Lactobacillus) in $62 \%$ of cases. These results agreed with the findings reported by Razzak et al. in Iraq[4] and Larsen and Monif in USA[5]. The lactobacilli are considered as the first line of the immune system in vagina to attack potential pathogens. According to these results, the patients were categorized into two groups, infectious and non- infectious vaginitis. The infectious group includes patients with bacterial vaginosis $(E$. coli) and yeast infection with Candida spp. (figure 1). The patients with normal flora mainly which was mainly Lactobacillus spp were considered as non-infectious vaginitis.

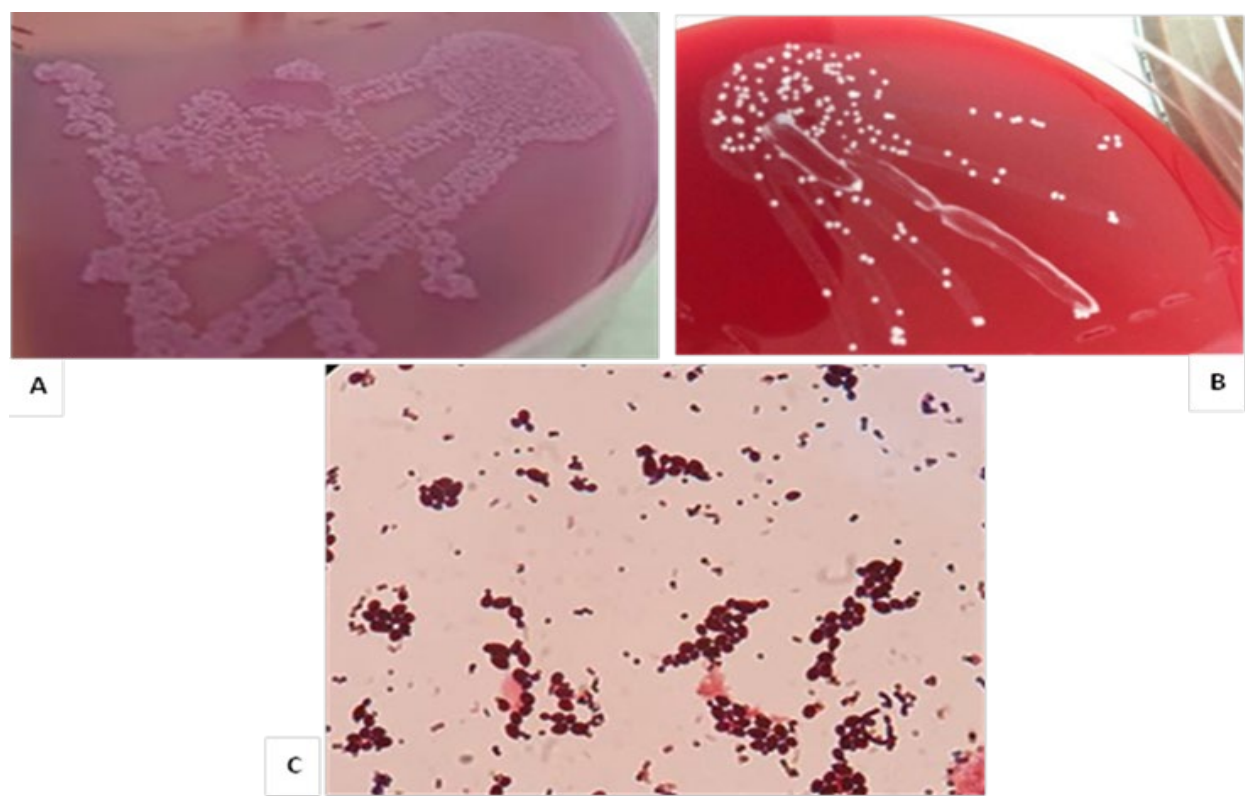

Figure 1: Vaginal culture and microscopic examination

A. E. coli colonies on MacConky agar after $24 \mathrm{~h}$ incubation at $37^{\circ} \mathrm{C}$ B. Candida on blood agar after 48 incubation at $37^{\circ} \mathrm{C} \mathrm{C}$. Gram-stained of yeast cultures was observed under light microscopy.

The ages of women included in this study were from 20 to 79 years, with most patients (18) aged between 25-35 years (Table 1). All patients that participated in this study were married and most of them were women of childbearing age. The prevalence of infection may be due to high sexual activity and the use of contraceptives among this age group, which might increase the possibility of genital tract infections [6]. In contrast only 11 of the patients were above 47 years of age. 45 patients inhabit to urban areas and just 5 are from rural areas. Their literacy ranged from primary level $(42 \%)$ to graduate level $(40 \%)$, while $18 \%$ were illiterate. The majority of patients $(84 \%)$ were unemployed. 
The result of this study had showed the significant association between infectious vaginosis with education level ( $p$ value 0.02). However, no significant association was observed with other demographic parameters such as occupation, residence and age groups between infectious and non-infectious groups. This result might reflect the small size of the study population. Ranjit et al. found that patients with genital tract symptoms were frequently from populations with low socioeconomic status [7].

Table 1: distribution of demographic data between infectious and non-infectious groups

\begin{tabular}{|c|c|c|c|c|c|}
\hline \multirow{2}{*}{\multicolumn{2}{|c|}{ Variables }} & $\begin{array}{l}\text { Infectious vaginitis } \\
\text { (19) }\end{array}$ & $\begin{array}{l}\text { Non- infectious } \\
\text { vaginitis (31) } \\
\end{array}$ & Total & \multirow[t]{2}{*}{ P-value } \\
\hline & & No (\%) & No $(\%)$ & No & \\
\hline $\operatorname{Age}($ Mean \pm & & $36 \pm 14$ & $38 \pm 13$ & $37.5 \pm 12.9$ & \\
\hline \multirow{4}{*}{ Age groups } & Less than 25 & $4(50)$ & $4(50)$ & 8 & \multirow{4}{*}{0.199} \\
\hline & $25-35$ & $9(50)$ & $9(50)$ & 18 & \\
\hline & $36-46$ & $2(15.4)$ & $11(84.6)$ & 13 & \\
\hline & More than 47 & $4(36.4)$ & $7(63.6)$ & 11 & \\
\hline \multirow{3}{*}{$\begin{array}{l}\text { Education } \\
\text { level }\end{array}$} & Illiterate & $3(100)$ & $0(0)$ & 3 & \multirow{3}{*}{0.024} \\
\hline & $\begin{array}{l}\text { Primary } \\
\text { school }\end{array}$ & $4(26.7)$ & $11(73.3)$ & 15 & \\
\hline & Graduated & $7(63.6)$ & $4(36.4)$ & 11 & \\
\hline \multirow{3}{*}{ Occupation } & House wife & $17(40.5)$ & $25(59.5)$ & 42 & \multirow{3}{*}{0.808} \\
\hline & Student & $2(28.6)$ & $5(71.4)$ & 7 & \\
\hline & Worker & $0(0)$ & $1(100)$ & 1 & \\
\hline \multirow{2}{*}{ Residency } & Urban & $16(35.6)$ & $29(64.4)$ & 45 & \multirow{2}{*}{0.335} \\
\hline & Rural & $3(60)$ & $2(40)$ & 5 & \\
\hline
\end{tabular}

The evaluation of the possible risk factors which might be associated with vaginitis was one of the main objectives of this study. The study found that the majority of women had history of previous infections in both infectious and non-infectious vaginitis groups as shown in table 2 . This may be due to improper medication or previously unrecognized complications. Miscarriage was the second most common risk factor in this study, which is contrary to the results of a study carried out by Giakoumelou et al. (2016)[8]. Bacterial vaginosis has been associated with premature delivery and with miscarriage (Tavo, 2013)[9]. Other risk factors were observed in this study such as hormonal imbalance and diabetes. Explanation regarding its basis includes that diabetes alters host defense (Mascarenhas et al. 2012). Finally, only four out of fifty women from infectious and non-infectious groups have sexually infected partners. All of the risk factors that were assessed in this study showed no significant contribution between the infectious and non-infectious groups; this is may be due to the small size of the population study. The limitation in sample size was due to the clinicians prescribing treatments to the patients based on clinical examination without performing any lab examinations. Additionally, there can be a chance that viral vaginitis may have a role in the infection, but this could not be ascertained because diagnosis requires sophisticated techniques for isolation which were not available at the time of this study. Finally, non-infectious vaginitis is another possible cause of genital tract symptoms.

In this study the most common symptom present among patients with infectious vaginitis group was itching (38.5\%) and smelly discharge (40\%). On the other hand, $61.5 \%$ and $60 \%$ of patients with non-infectious vaginitis group had itching and smelly discharge respectively, as shown in Table 2. However, statistically the association was not significant for both symptoms (0.9 and 0.7) respectively. Vaginal discharge is one of the most common symptoms of vaginitis and itching is more common in bacterial and candidal vaginitis. Redness around 
vagina and pain during sex was found in $53.3 \%$ and $37.5 \%$ of infectious group respectively. Among non-infectious group, $62.5 \%$ had pain during sex. This finding is agreement with the result of Paladine \& Desai (2018) who reported that non-infectious vaginitis, atrophic vaginitis, is usually associated with pain during sex or urination. Swelling of the vagina was observed in $56.5 \%$ of non-infectious group which might be caused by allergies, sexually transmitted infections (STIs) and cysts which are not included in this study [10].

Table 2: Distribution of risk factors and symptoms between infectious and non-infectious microorganisms

\begin{tabular}{|c|c|c|c|c|c|}
\hline \multicolumn{2}{|l|}{ Variables } & \multirow{2}{*}{$\begin{array}{l}\text { Infectious } \\
\text { vaginitis (19) } \\
\text { No (\%) }\end{array}$} & \multirow{2}{*}{$\begin{array}{l}\text { Non- infectious } \\
\text { vaginitis (31) } \\
\text { No }(\%)\end{array}$} & \multirow{2}{*}{ Total } & \multirow{2}{*}{ P-value } \\
\hline Risk factors & & & & & \\
\hline \multirow{2}{*}{ Diabetes } & Yes & $1(20)$ & $4(80)$ & 5 & \multirow{2}{*}{0.637} \\
\hline & No & $27(60)$ & $18(40)$ & 45 & \\
\hline \multirow{2}{*}{$\begin{array}{l}\text { The infection } \\
\text { present in } \\
\text { partner }\end{array}$} & Yes & $3(75)$ & $1(25)$ & 4 & \multirow[b]{2}{*}{0.147} \\
\hline & $\overline{\text { No }}$ & $16(65.2)$ & $30(34.8)$ & 46 & \\
\hline \multirow{2}{*}{$\begin{array}{l}\text { History of fungal } \\
\text { infection }\end{array}$} & Yes & $13(46.4)$ & $15(53.6)$ & 28 & \multirow{2}{*}{0.166} \\
\hline & No & $6(27.3)$ & $16(72.7)$ & 22 & \\
\hline \multirow{2}{*}{ Miscarriage } & Yes & $11(40.7)$ & $16(59.3)$ & 27 & \multirow{2}{*}{0.665} \\
\hline & No & $8(34.8)$ & $15(65.2)$ & 23 & \\
\hline \multirow{2}{*}{$\begin{array}{l}\text { Hormonal } \\
\text { imbalance }\end{array}$} & Yes & $3(30)$ & $7(70)$ & 10 & \multirow{2}{*}{0.726} \\
\hline & No & $15(38.5)$ & $24(61.5)$ & 39 & \\
\hline \multirow{2}{*}{$\begin{array}{l}\text { Infection present } \\
\text { before }\end{array}$} & Yes & $16(45.7)$ & $19(54.3)$ & 35 & \multirow{2}{*}{0.310} \\
\hline & No & $3(25)$ & $9(75)$ & 12 & \\
\hline \multirow{2}{*}{ Use antibiotics } & Yes & $3(75)$ & $1(25)$ & 4 & \multirow[t]{2}{*}{0.303} \\
\hline & No & $13(40.6)$ & $19(59.4)$ & 32 & \\
\hline \multicolumn{6}{|l|}{ Symptoms } \\
\hline \multirow{2}{*}{ Swelling } & Yes & $4(44.4)$ & $5(56.5)$ & 9 & \multirow{2}{*}{0.660} \\
\hline & No & $15(36.6)$ & $26(63.4)$ & 41 & \\
\hline \multirow{2}{*}{ Itching } & Yes & $10(38.5)$ & $16(61.5)$ & 26 & \multirow{2}{*}{0.944} \\
\hline & No & $9(37.5)$ & $15(62.5)$ & 24 & \\
\hline \multirow{2}{*}{ Burning } & Yes & $4(28.6)$ & $10(71.4)$ & 14 & \multirow{2}{*}{0.522} \\
\hline & No & $15(41.7)$ & $21(58.3)$ & 36 & \\
\hline \multirow{2}{*}{ Pain intercourse } & Yes & $9(37.5)$ & $15(62.5)$ & 24 & \multirow{2}{*}{0.944} \\
\hline & $\mathrm{No}$ & $10(38.5)$ & $16(61.5)$ & 26 & \\
\hline \multirow{2}{*}{ Redness } & Yes & $8(53.3)$ & $7(46.7)$ & 15 & \multirow{2}{*}{0.144} \\
\hline & No & $11(31.4)$ & $24(68.6)$ & 35 & \\
\hline \multirow{2}{*}{ Discharge } & Yes & $12(40)$ & $18(60)$ & 30 & \multirow{2}{*}{0.721} \\
\hline & No & $7(35)$ & $13(65)$ & 20 & \\
\hline
\end{tabular}

The microscopic examination of the wet-mount method was done for 42 patients. This method was used for detecting microorganisms, pus cells, RBC, and epithelial cells. Microscopic examination of patient's vaginal swabs revealed that $63.6 \%$ of infectious group had high level of epithelial cells $++(>10)$, while the most patients with non-infectious vaginitis had $+(10)$ or less epithelial cell in the microscopic field. The presence of epithelial cells was significantly associated with infectious vaginitis $(P$ value 0.04$)$. However, regarding the presence of the pus cells and RBCc, the variation was not significant as shown in table 3 , where $90 \%$ and only $30 \%$ of patients have blood. 
The laboratory evaluation includes unstained wet mount was used for detecting microorganisms, pus cells, RBC, and epithelial cells. The presence of epithelial, pus and $\mathrm{RBCc}$ are indicators of infection conforming to literature [11]. No microorganisms were detect by this method accept one sample in which yeast was present. Experience has shown that the biggest problem lays in the basic infectiological diagnostic procedures. Diagnosis by either wet mount or culture depends on an experienced microscopist. Wet mount microscopy for detection of vaginal pathogens is a rapid, inexpensive screening technique, but has low sensitivity [12].

Table 3: The results of Direct microscopic examinations of Infectious And Non-infectious Groups.

\begin{tabular}{|c|c|c|c|c|c|}
\hline \multicolumn{2}{|c|}{ Laboratory tests } & \multirow{2}{*}{$\begin{array}{c}\begin{array}{c}\text { Infectious vaginitis } \\
\text { No }(\%)\end{array} \\
14(33.3)\end{array}$} & \multirow{2}{*}{$\begin{array}{c}\begin{array}{c}\text { Non- infectious } \\
\text { vaginitis } \\
\text { No }(\%)\end{array} \\
28(66.7) \\
\end{array}$} & \multirow{2}{*}{$\begin{array}{c}\begin{array}{c}\text { Total } \\
\text { No }\end{array} \\
42 \\
\end{array}$} & \multirow[t]{2}{*}{ P-value } \\
\hline Cases & & & & & \\
\hline \multirow[t]{3}{*}{ Epithelial cells } & + & $6(23.1)$ & $20(76.9)$ & 26 & 0.049 \\
\hline & ++ & $7(63.6)$ & $4(36.4)$ & 11 & \\
\hline & +++ & $1(25)$ & $3(75)$ & 4 & \\
\hline \multirow[t]{3}{*}{ Pus } & + & $4(44.4)$ & $5(55.6)$ & 9 & 0.559 \\
\hline & ++ & $8(34.8)$ & $15(65.2)$ & 23 & \\
\hline & +++ & $2(20)$ & $8(80)$ & 10 & \\
\hline \multirow[t]{3}{*}{ RBCs } & + & $12(42.9)$ & $16(57.1)$ & 28 & 0.197 \\
\hline & ++ & $2(15.4)$ & $11(84.6)$ & 13 & \\
\hline & ++++ & $0(0)$ & $1(100)$ & 1 & \\
\hline
\end{tabular}

\section{CONCLUSION AND RECOMMENDATION}

The diagnosis of vaginal infection among women in Maternity hospital in Sulaimani is basically dependent on clinical symptoms without performing any laboratory examinations. The treatment is usually includes both antibacterial antifungal agents. In this study different diagnosis methods were used to detect the causes of vaginitis such as direct microscopic examination, culturing and gram stain method. Based on the present study results, there was different types of vaginitis including non-infectious vaginitis and infectious vaginitis (bacterial and yeast infection). Therefore, it is essential to perform laboratory examination for the patients to detect the causative agents of vaginitis. Vaginitis can be partially diagnosed with physical examination; however the microscopic examination and culture analysis are very important to detect the presence of the pathogens. The study recommends more laboratory diagnosis for early and accurate diagnosis such as vaginal $\mathrm{pH}$, biochemical tests, whiff test. Unfortunately, identification of the exact species of candida was not done in this study. Therefore, isolation and identification tests of vaginal Candida species such as germ tube test or PCR are recommended.

\section{REFERENCE}

[1] A. M. Hasan, "Review on : Vaginitis . A problem to be solved!!," J. Pharm. Chem. Biol. Sci., vol. 4, no. 1, pp. 104-110, 2016.

[2] J. van Schalkwyk et al., "Vulvovaginitis: Screening for and Management of Trichomoniasis, Vulvovaginal Candidiasis, and Bacterial Vaginosis," J. Obstet. Gynaecol. Canada, vol. 37, no. 3, pp. 266-274, 2015, doi: 10.1016/S1701- 2163(15)30316-9.

[3] H. L. Paladine and U. A. Desai, "Vaginitis: Diagnosis and Treatment," Am. Fam. Physician, vol. 97, no. 5, pp. 321-329, 2018.

[4] M. S. A. Razzak, A. H. Al-charrakh, and B. H. Al-greitty, "Relationship between lactobacilli and opportunistic bacterial pathogens associated with vaginitis," vol. 3, no. 4, 2011, doi: 10.4297/najms.2011.3185.

[5] B. Larsen and G. R. G. Monif, "Understanding the bacterial flora of the female genital tract," Clin. Infect. Dis. an Off. Publ. Infect. Dis. Soc. Am., vol. 32, no. 4, pp. e69-77, 2001, doi: 10.1086/318710.

[6] A. Bahram, B. Hamid, and T. Zohre, "Prevalence of bacterial vaginosis and impact of genital hygiene practices in non-pregnant women in Zanjan, Iran," Oman Med. J., vol. 24, no. 4, pp. 288-293, 2009, doi: 
10.5001/omj.2009.58.

[7] E. Ranjit, B. R. Raghubanshi, S. Maskey, and P. Parajuli, "Prevalence of bacterial vaginosis and its association with risk factors among nonpregnant women: A hospital based study," Int. J. Microbiol., vol. 2018, 2018, doi: 10.1155/2018/8349601.

[8] S. Giakoumelou, N. Wheelhouse, K. Cuschieri, G. Entrican, S. E. M. Howie, and A. W. Horne, "The role of infection in miscarriage," Hum. Reprod. Update, vol. 22, no. 1, pp. 116-133, 2016, doi: 10.1093/humupd/dmv041.

[9] Tavo V., "Tavo V. Prevalence of Mycoplasma hominis and Ureaplazma urealyticum among women of reproductive age in Albania.," Med Arch., vol. 67, no. 1, 2013.

[10] G. A. Lakshmi, K; Aishwarya, J.R.; Chitralekha, S; Menezes, "Review on Infectious Vaginitis Research Journal of Pharmaceutical , Biological and Chemical Sciences Review on Infectious Vaginitis Lakshmi K*, Aishwarya JR, Chitralekha S, and Menezes GA July-September," Res. J. Pharm. Biol. Chem. Sci., vol. 4 no. 3, pp. 679-688, 2013.

[11] C. Edru, Sylvie Pd; Nicolas, Meda Md, Msc; Mohamed, Fofana Md; Georges, Soula Md, Msc; Jules, Bazié André Md; Jean Paul, "Etiologic_Study_of_Genitourinary_Infections_in.11 (1).pdf," Sex. Transm. Dis., vol. 23, no. 2, p. p 151-156, 1996 .

[12] S. C. M. Madhumati J Patil, Jyoti M Nagamoti, "Diagnosis of Trichomonas vaginalis from vaginal specimens by wet mount microscopy, in pouch TV culture system, and PCR," J Glob Infect Dis, vol. 4, no. 1, pp. 22-25, 2012.

Kurdistan Journal of Applied Research $\mid 4^{\text {th }}$ International Conference on the Health and Medical Science: Medical Researches Improve Life Quality (ICHMS 2020) | 159 